San Jose State University

SJSU ScholarWorks

Master's Theses

Master's Theses and Graduate Research

1996

\title{
The effect of corporate culture on the retention of learning and transfer of training
}

Lucia J. Erwin

San Jose State University

Follow this and additional works at: https://scholarworks.sjsu.edu/etd_theses

\section{Recommended Citation}

Erwin, Lucia J., "The effect of corporate culture on the retention of learning and transfer of training" (1996). Master's Theses. 1359.

DOI: https://doi.org/10.31979/etd.sw6e-nyca

https://scholarworks.sjsu.edu/etd_theses/1359

This Thesis is brought to you for free and open access by the Master's Theses and Graduate Research at SJSU ScholarWorks. It has been accepted for inclusion in Master's Theses by an authorized administrator of SJSU ScholarWorks. For more information, please contact scholarworks@sjsu.edu. 


\section{INFORMATION TO USERS}

This manuscript has been reproduced from th: microfilm master. UMI films the text directly from the original or copy submitted. Thus, some thesis and dissertation copies are in typewriter face, while others may be from any type of computer printer.

The quality of this reproduction is dependent upon the quality of the copy submitted. Broken or indistinct print, colored or poor quality illustrations and photographs, print bleedthrough, substandard margins, and improper alignment can adversely affect reproduction.

In the unlikely event that the author did not send UMI a complete manuscript and there are missing pages, these will be noted. Also, if unauthorized copyright material had to be removed, a note will indicate the deletion.

Oversize materials (e.g., maps, drawings, charts) are reproduced by sectioning the original, beginning at the upper left-hand comer and continuing from left to right in equal sections with small overlaps. Each original is also photographed in one exposure and is included in reduced form at the back of the book.

Photographs included in the original manuscript have been reproduced xerographically in this copy. Higher quality 6" $\times 9$ " black and white photographic prints are available for any photographs or illustrations appearing in this copy for an additional charge. Contact UMI directly to order.

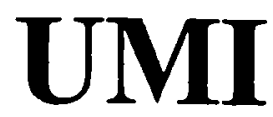

A Bell \& Howell Information Company 300 North Zeeb Road, Ann Arbor MI 48106-1346 USA 



\title{
THE EFFECT OF CORPORATE CULTURE \\ ON THE RETENTION OF LEARNING \\ AND TRANSFER OF TRAINING
}

\author{
A Thesis \\ Presented to \\ the Faculty of the Department of Psychology \\ San Jose State University \\ In Partial Fulfillment \\ of the Requirements for the Degree \\ Master of Science
}

by

Lucia J. Erwin

December, 1996 
UMI Number: 1382563

\section{Copyright 1996 by \\ Erwin, Lucia J.}

All rights reserved.

UMI Microform 1382563

Copyright 1997, by UMI Company. All rights reserved.

This microform edition is protected against unauthorized copying under Title 17, United States Code.

\section{UMI \\ 300 North Zeeb Road \\ Ann Arbor, MI 48103}


(C) 1996

Lucia J. Erwin

ALL RIGHTS RESERVED 
APPROVED FOR THE DEPARTMENT OF PSYCHOLOGY

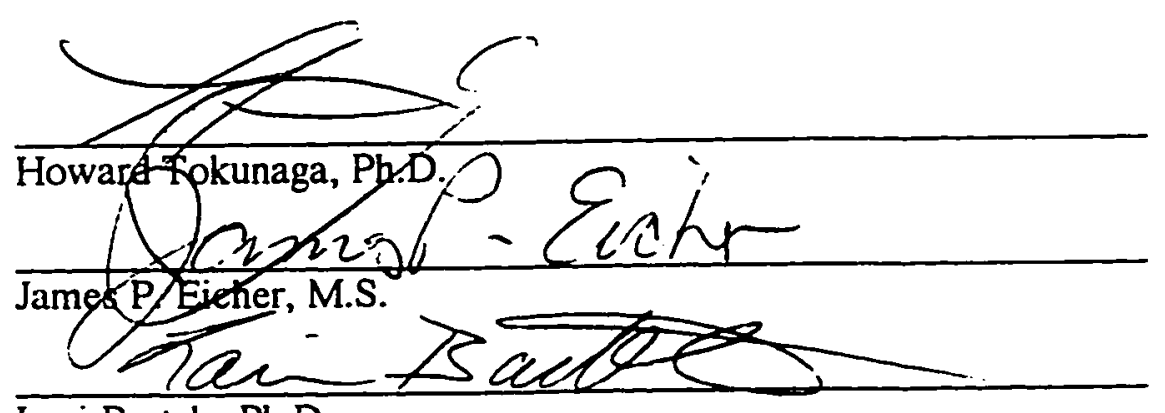

Lori Bartels, PhD.

APPROVED FOR THE UNIVERSITY

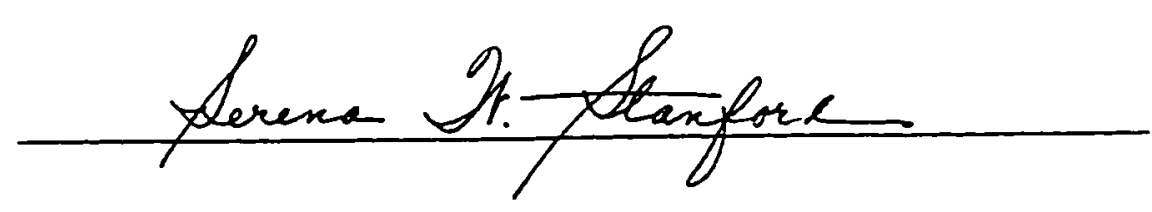




\section{ABSTRACT \\ THE EFFECT OF CORPORATE CULTURE ON THE RETENTION OF LEARNING AND TRANSFER OF TRAINING \\ by Lucia J. Erwin}

The purpose of this study was to examine the effect of corporate culture on retention of learning and transfer of training. Subjects consisted of 52 employees from two high-tech organizations who attended a training program on legal issues in management. Participants completed an evaluation tool prior to the training, immediately after the training, and two months after the training. Participants were also interviewed two months after the training.

Results from analyses of variance showed that participants from both organizations retained the knowledge and skills they had learned two months after completing the training. Results from a t-test conducted on interview results showed that participants from the first organization, which had a relaxed corporate culture that was supportive of training. exhibited a significantly higher degree of transfer of training than did participants from the second organization, which had a formal corporate culture and was less supportive of training. 


\section{For my mother,}

who taught me that dreams come true

and

that anything is possible to have, if I want it. 


\section{ACKNOWLEDGMENTS}

Obtaining a masters degree is a series of tasks with dozens of people to assist along the journey. However, there are a few individuals whose assistance with my journey was outstanding.

I would like to thank Howard Tokunaga and Lori Bartels for working within my tight timelines. I'd like to thank Jim Eicher for his support and encouragement--he truly is a good friend.

I would like to thank Candice Chorjel for all her love and support in helping me grow up and see my potential. I have come so far with her help.

I would like to thank Tracy Graham for her support in bringing this thesis alive. I could not have accomplished this task without her sponsorship and e-mail notes.

I would like to thank Linda Alepin, Patti Ferguson, and Rose Singer. These three ladies gave me an arena to demonstrate my skills and supported me along the way. Working with them and with Amdahl was my springboard to success. They helped boost my confidence. "Just because you are perfect and I love you."

I would like to give special thanks to Alex Stowbunenko for his love. support. guidance, and understanding. I would like to thank him for doing the housework while I wrote my thesis, for letting me have time to myself to study, and for being my courier to SJSU on a moment's notice. I'm so happy to have someone as wonderful as he is in my life to share this accomplishment. I love him very much. 


\section{TABLE OF CONTENTS}

SECTION

PAGE

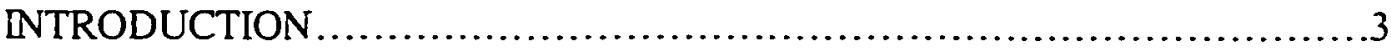

Evaluation of Training..................................................

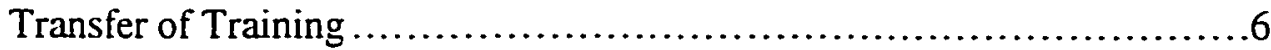

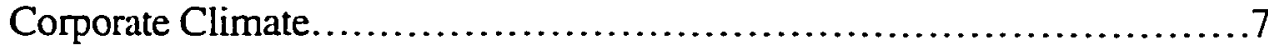

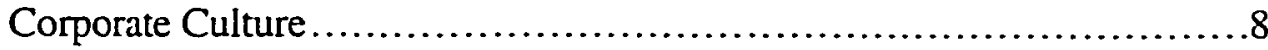

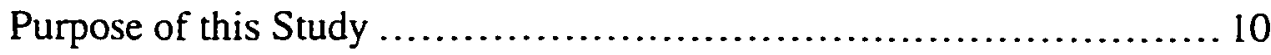

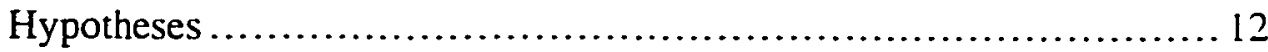

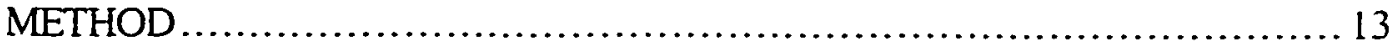

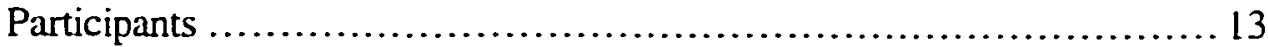

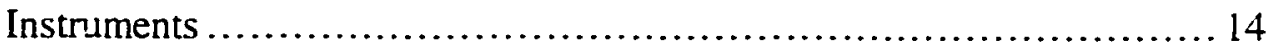

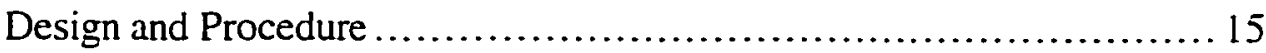

Retention of Learning......................................... 15

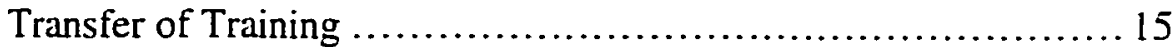

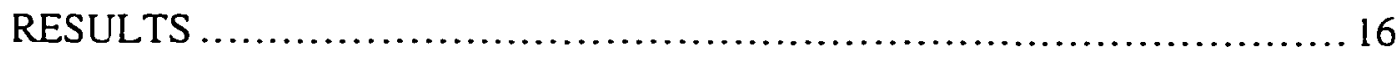

DISCUSSION ........................................................... 18

Implications of This Study ......................................... 20

Strengths and Limitations of This Study .............................. 25

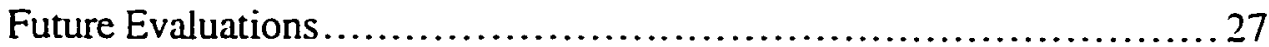

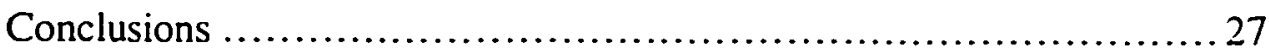

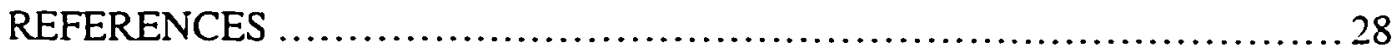




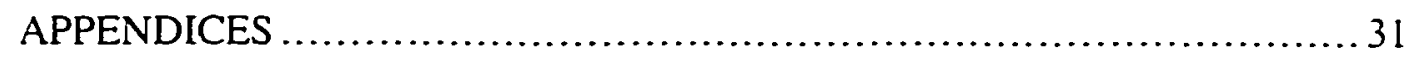

Appendix A. Evaluation Tool........................................ 31

Appendix B. Transfer of Training Interview Questions................... 34

Appendix C. Signed Approval Form ..................................... 35 


\section{LIST OF TABLES}

TABLE PAGE

1. Means and Standard Deviations of Organization Scores by Time Period 
The Effect of Corporate Culture on the Retention of Learning and Transfer of Training

Lucia J. Erwin

San Jose State University

Running head: CORPORATE CULTURE

Footnotes

Requests for reprints should be sent to Lucia J. Erwin, Department of Psychology. San Jose State University, San Jose, California 95192 


\begin{abstract}
The purpose of this study was to examine the effect of corporate culture on retention of learning and transfer of training. Subjects consisted of 52 employees from two high-tech organizations who attended a training program on legal issues in management. Participants completed an evaluation tool prior to the training, immediately after the training, and two months after the training. Participants were also interviewed two months after the training. Results from analyses of variance showed that participants from both organizations retained the knowledge and skills they had learned two months after completing the training. Results from a t-test conducted on interview results showed that participants from the first organization, which had a relaxed corporate culture that was supportive of training, exhibited a significantly higher degree of transfer of training than did participants from the second organization, which had a formal corporate culture and was less supportive of training.
\end{abstract}


The Effect of Corporate Culture on the Retention of Leaming and Transfer of Training Employer-sponsored training is an enterprise so vast and amorphous that it has been called America's "shadow education system" (McCune, 1994). It is a multi-billiondollar industry that influences the lives and careers of millions of employees. An annual survey conducted in 1995 by Training magazine found that training budgets for organizations within the United States totaled \$52.2 billion, an increase of $\$ 6.8$ billion from 1990. That figure is close to the total spent on post-secondary education in the United States (McCune, 1994). One local high-technology organization with an employee population of 5.200 spent $\$ 2.6$ million on training employees in 1995 (Singer, 1996). In 1994. the annual education and training budget for GTE Corp. was $\$ 100$ million. The average corporate training budget is $6 \%$ of the total corporate budget, a significant percentage of the total budget of Fortune 500 companies (Singer, 1996). Yet with all the resources given to providing training programs, the process of evaluating these programs is neglected. The purpose of this study is to explore the relationship between two different organizational cultures (a factor outside the formal training context) and the retention of learning and transfer of acquired skills back to the job.

It is estimated that less than $10 \%$ of a company's training budget is allocated to the evaluation process (Black, 1991) and that only about $15 \%$ of companies measure behavior change that results from training programs (Garavagia, 1993). Black suggests that approximately $80 \%$ of the evaluation process measures only the participants' reactions to the program. The majority of a training budget is spent on factors within the formal training context, such as the design, development, and educational content (Singer. 1996).

With the "new" work rules of the 90's. (work harder, faster, and with far less employees), training departments are giving little attention and discipline to formal evaluation processes. This is partially because they are short-staffed and have increased 
responsibilities. In fact, the entire structure of corporate training departments has undergone a business process re-engineering. A typical training department with twenty employees and separate job functions. such as consultants, instructional designers. facilitators, and instructors, no longer exists. Training departments have been downsized and the survivors must be able to perform all of these functions, in addition to evaluation (Shandler, 1996).

\section{Evaluation of Training}

There have been several training evaluation models developed (Gilbert, 1978: Kearsely, 1982: Phillips, 1983; Rummler, 1976), but one of the most widely known is the four-step evaluation model developed by D. L. Kirkpatrick. Kirkpatrick has written several articles about his model since he introduced it in 1959. In 1994, Kirkpatrick elaborated on his model in his book Evaluating Training Programs: The Four Levels.

Kirkpatrick's approach is based on four levels, each one built on the previous level. These four levels are: (1) Reaction, (2) Learning, (3) Behavior, and (4) Results. Reaction measures how well participants like a training program, the content, the trainer, the methods employed, the logistical aspects, and their general attitudes toward any part of the program. Reaction forms or "smile sheets" are distributed to the trainees at the end of the training program. Most often this information is used to alter the training program in insignificant ways, such as moving the training to a different room or shortening training activities.

The second level of evaluation, Learning, measures the extent to which participants change attitudes, improve knowledge, and/or increase skills as a result of attending the program. Tools to measure Learning are generally paper-and-pencil tests, which measure knowledge and attitudes, and performance tests, which measure skills.

Behavior measures the extent to which a change in behavior has occurred back on the job because a participant attended a training program. This is also referred to as transfer 
of training. To allow accurate attribution of a change in behavior to the learning objectives of a training program, it is important to first measure acquired learning.

The fourth level, Results, is the most critical in relation to the overall success of an organization. This is defined as the final business results that occur due to a participant's attendance of a training program, such as increased production. improved quality. decreased costs, or increased sales. This final step of evaluation assesses the cost-benefit results of a training program. An example of Kirkpatrick's complete model would be if an organization had increased sales as a result of behavioral change acquired by participants learning new skills and being satisfied with the training.

In the past, evaluation studies have been conducted on various training programs by individuals in the educational sector and have usually focused on factors within the formal training context, such as the design and content of training. The central question has been. "Did the training work: did participants learn from the training program?" (Roullier \& Goldstein, 1992). This perspective does not provide much insight into whether or not training is used back on the job.

A wider perspective is needed for a better understanding of what makes participants transfer what they have learned in a training program to their everyday work. The question should be, "How and why did the training work, or not work?" It is likely that many individual and organizational factors outside the formal training context influence the effectiveness of training.

Questioning why training works is critical to corporate training departments that currently need to show the impact that participation in training programs has on an organization's bottom line, in order to retain their training budgets. Corporate training departments should be focusing on what organizational factors outside the training classroom influence the effectiveness of training. It is believed that training effectiveness. 
in terms of the retention of learning and transfer of training back to the job. is not solely affected by the design and content of training programs (Goldstein, 1986).

\section{Transfer of Training}

It is important to measure learning because no change in behavior can be expected unless one or more of the learning objectives of a training program have been accomplished (Kirkpatrick, 1994). Baldwin and Ford (1988) theorize that transfer of training has three major determinants: trainee characteristics, training design, and work environment.

Trainee characteristics determine whether an individual will initially learn and subsequently transfer new skills. An example of a trainee characteristic is learning style. Based on neurolinguistic communications (Eicher, Johns, \& Bearley, 1996), training participants have been found to have pre-determined modes of receiving information: visual, kinesthetic, and auditory. For example, if a training program is conducted exclusively in an auditory manner, it may be more difficult for a participant with a visual learning style to learn the content of the training, and thus to transfer the skills back to the job.

Training design includes such factors as the adult learning principles utilized when designing the training, the sequence of learning objectives, and the content of the training program. According to Adult Learning Theory, adult participants retain more information when the content of a training program is relevant to their work and when the training format is participatory and fun.

However, the work environment to which the participant will return plays a major role in the transfer of training process. In organizations where a participant's manager is not supportive of training, the opportunity is not available to utilize skills learned in the training program. or the employee is negatively rewarded for utilizing the new behavior. the retention of learning and transfer of training will be affected (Goldstein, 1986). Even if material is initially learned, without support, resources, and the opportunity to use the new 
skills, generalization and transfer back to the job is unlikely to occur (Ford. Quinones. Sego, \& Sorra, 1992).

Organizational support for training has been cited as a key work environment variable affecting the learning and transfer process (Baldwin \& Ford. 1988; Fleishman. 1953; House, 1968; Noe, 1986; Tannenbaum \& Yukl, 1992). As Huczynski and Lewis (1980) contend, participants will be more motivated to attend training, to learn. to retain information, and to transfer new skills back to the job if they believe training programs are perceived by their organization to be important.

\section{Corporate Climate}

Studies have been conducted to examine the impact of organizational climate on transfer of training (Rouiller \& Goldstein, 1992). Studies dating back to 1939 have examined the evaluation of training and organizational climate. Litwin and Stringer (1968) defined organizational climate as individual perceptions regarding a number of situational characteristics, such as responsibility, rewards, structure, risk, etc. Employees' perceptions of these areas vary on a day-to-day basis and thus the corporate climate may change rapidly and continuously in an organization, based on internal or external factors.

Fleishman, Harris, and Buntt (1955) conducted the first study that suggested that a supportive climate is a factor in the transfer of leaming to the job situation. They conducted a training program that resulted in managers being more considerate of their employees. but in a follow-up investigation it was found that the effects of the training had disappeared. To determine why this occurred, Fleishman et al. conducted a series of interviews which suggested that the effects disappeared because the supervisors of the trained managers were not supportive of the goals of the training program.

Recently, Rouiller and Goldstein (1992) conducted a study to determine whether an organizational transfer climate exists on the job that helps to determine if behavior learned in training will actually be transferred back to the job. They found that perceptions about 
the climate to which trainees returned were directly related to the use of the supervisory behaviors that the trainees were taught in a formal training program. These results validate that factors outside the formal training context are important to the transfer of training.

\section{Corporate Culture}

Although studies have focused on the effects of organizational climate, no empirical research has been conducted to determine the effect of corporate culture on the transfer of training. A reason for this is that the study of culture in corporate research is relatively new. In the early 1980's, the concept of corporate culture was introduced in four books: Corporate Culture: The Rites and Rituals of Organizational Life (Deal \& Kennedy, 1982). Theory Z (Ouchi. 1981), The Art of Japanese Management (Pascale \& Athos, 1981), and

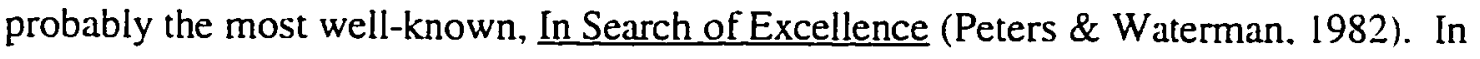
1983, both Administrative Science Quarterly and Organizational Dynamics devoted issues to the discussion of corporate culture.

According to Sackman (1991), there are three main conceptual perspectives on culture in the organizational literature: (1) the variable perspective, (2) the cognitive perspective, and (3) the holistic perspective. The variable perspective focuses on the expression or behavioral manifestation of culture. Culture is defined as "the way we do things around here," that is, behavioral norms, rites, rituals, and jargon expressed by employees. The cognitive, or "ideational" perspective, focuses on ideas, concepts, beliefs. and values. These factors are thought to be the core of the creation of a corporate culture. The cognitive elements of culture are considered to be "organized knowledge" that are socially constructed. This knowledge provides a model by which organizational members perceive, integrate, and interpret information in daily work.

The holistic perspective incorporates elements from both the variable and cognitive perspectives. This approach integrates both the overt (observable) and covert (underlying) components of a culture into a unified whole. Culture is defined as set ways of thinking. 
feeling, and behaving, and is acquired and transmitted by visible and salient symbols. Corporate culture has a core set of selected values, ideas, and assumptions that have been historically determined and that will shape future action. as well as a set of corporate activities and behavioral patterns that characterize life in an organization.

One researcher who has developed the holistic perspective is Schein (1985). Schein defines corporate culture as "the pattern of basic assumptions that a given group has invented, discovered, or developed in learning to cope with its problems of external adaptation and internal integration. and that have worked well enough to be considered valid, and therefore. to be taught to new members as the correct way to perceive, think, and feel in relation to those problems" (p. 3). Plainly stated, Schein developed his holistic approach to distinguish cultures through visual artifacts, behaviors, and underlying assumptions.

Visual artifacts can be defined as the organizational structure, architecture. technology, and office layout used for physical needs, manner of dress, and public documents or image. Behaviors can be defined as the behavior norm that is expected of an employee. This would include the visual or audible behavior patterns that the work environment would deem acceptable. For example, it may be inappropriate for employees to speak out in meetings and offer ideas in one company, but it may be expected in another company. Lastly, the underlying assumptions are those shared values that each employee perceives. thinks, and feels in a collective environment, thus defining the basis of each corporate culture. These assumptions are manifested through the visual artifacts and behaviors. For example, employees in a start-up organization may share the value of working long hours in a day until the job is completed, which would be manifested in communication forums (hallway meetings) and visual artifacts (food provided on-site).

Examples of these defined corporate cultures surround us and we encounter them daily. A customer shopping at Nordstrom (a department store) would see the culture of 
customer service: the needs of the customer are a higher priority than the need for an employee to follow company policy. In contrast, a customer may enter a Citibank (a financial institution) on the same day, where the culture is to value corporate policy above customer service.

While a majority of the research in the 1980's focused on defining and acknowledging varying corporate cultures, it is the research of the 1990's that focuses on the relationship between corporate culture and organizational success. Denison (1992) states that the reasons for the focus on corporate culture and its impact on an organization's effectiveness are the increase in mergers, declining productivity, and global competition. Both Kotter and Heskett (1992) and Denison (1992) have conducted studies on various organizations to examine the relationship between the overall economic success of public companies and these companies' cultures. These publications document that corporate culture is now being considered in relation to the operation and success of an organization. Purpose of This Study

The literature reviewed provides a strong foundation for this study. Training evaluation is a methodical process with various levels; however, previous studies have focused primarily on acquired learning versus transfer of learning back to the job. Factors outside the formal training context affect the transfer of skills acquired by participants. Specifically, studies have found that corporate climate is related to transfer of training and that transfer of training is built on learning and participant satisfaction. Recent research has explored the relationship between corporate culture and organizational effectiveness, but corporate culture has not been studied as a factor affecting retention of learning and transfer of training.

The purpose of this study is to explore the relationship between different organizational cultures (a factor outside the formal training context) and the retention of learning and transfer of acquired skills back to the job. This study will examine the effect 
of corporate culture on two high-technology organizations (referred to as Organization A and Organization B). The training program used in this study is a legal program covering sexual harassment, wrongful termination, equal employment opportunity, and affirmative action laws and regulations. By utilizing the same training program across both organizations, any effects on a participant's retention of learning and transfer of training can be attributed to the corporate culture of the organization in which the participant is employed.

Organization $\mathrm{A}$ is an American-owned, high-technology corporation with approximately 2000 employees. Its corporate headquarters are in Silicon Valley, California. The company was founded by three graduate students from a local university. Its corporate office is structured in campus-style, one-story buildings which are surrounded by landscaped grounds. Reading materials found in reception areas are usually trend magazines and community papers advertising music events. The dress code is casual and a common outfit worn by employees is a $t-s h i r t$, jeans, and tennis shoes. Free sodas and bags of popcorn are available in all break rooms and many workspaces have dart boards. posters, adult toys, and various other personal objects. In addition, there are several recreational clubs for employees to join, including tennis, skiing, and racquetball.

Organization A places a high value on training and developing managers. It has designed a curriculum of training programs a manager must complete within two years of hiring/promotion to a management position. This curriculum includes assignment of a mentor and projects to reinforce the learning acquired in the training programs. The first program new managers must complete is a week-long leadership course in which they become acclimated to the corporate culture. The training program used in this study is one of seven programs a manager must complete in order to meet curriculum requirements.

Organization B is an American company whose parent company is Japanese. It employs about 1800 employees and its corporate headquarters are in Silicon Valley. 
California. Its main buildings are three stories high and are situated close together. with walkways connecting them. The lobby was designed by a professional interior decorator. with annual reports for reading material. Employees follow a formal business dress code. with men wearing suits and ties and women wearing suits and nylons. Workspaces appear sterile, with little personal memorabilia. Employees appear reserved in conversational tone.

Managers from Organization B attend the training program used in this study to fulfill a requirement defined by a contract witn the Department of Labor of the United States. There is little support for the training received and this program is a stand-alone class that most managers are required to attend. To enroll in the training course. managers deal directly with an outside vendor, rather than with an internal resource.

Organizations that have created a value for training and have integrated that value into their culture, such as Organization $A$, have been found to have a positive impact on training. Alexander (1987) states that a combination of shared values and important skills provide the potential for a very effective training program. "Not only are managers given the opportunity to develop abilities that will increase their effectiveness, they are also provided with a structure that shows them how to maximize in a way that will benefit both themselves and the company" (p. 67).

\section{Hypotheses}

It is hypothesized that when the training function is an integral part of the corporate culture, as in Organization A, the retention of learning and transfer of training will be greater than in an organization in which the training function is not an integral part of the culture, such as Organization B.

The specific hypotheses to be investigated by this study are:

1. Scores taken after the training program is completed will be significantly higher than scores taken prior to the training program among participants employed at both 
Organization A and Organization B. This will indicate that participants learned the material presented in the course.

2. Among participants employed at Organization A, scores taken two months after the training program will not be significantly lower than scores taken immediately after the training program, indicating that learning was retained by participants.

3. Among participants employed at Organization B, scores taken two months after the training will be significantly lower than scores taken immediately after the training. This will indicate that retention of learning has not occurred.

4. The participants from Organization $A$ will report a significantly higher measurement of transfer of training than participants from Organization B.

\section{Method}

This study employed previously-collected data originally obtained by an external training company to evaluate a management training program, for the purpose of marketing and selling the program to prospective clients. When it was originally analyzed, all of the data was combined and organizational differences were not studied.

The training program attended by participants was a one-day prevention program on legal issues in management: harassment, wrongful termination, affirmative action guidelines, and equal employment opportunities. It was held in a neutral location and each program was conducted with intact organizational participants.

\section{Participants}

Employees from two organizations participated in this study. Each organization contracted the external training company to conduct the training program on a monthly basis. Participants of the study were chosen by their enrollment in the training program during a two-month period. Participants were enrolled on a voluntary or non-voluntary (enrollment by a participant was required by the participant's manager) basis. Each training participant was given the opportunity to decline to participate in the research study. 
Four of the training programs presented by the external training company were chosen at random. Out of the four programs chosen, 69 trainees participated in the study to measure learning acquired (the first post-test), 26 from Organization $\mathrm{A}$ and 43 from Organization B. Of the original 69 participants, 52 participants, 26 from Organization $A$ and 26 from Organization B, chose to complete a second post-test and to be interviewed. Only the 52 participants who completed both post-tests were retained for statistical analysis.

A total of 13 female participants, three from Organization $A$ and ten from Organization B, and 39 male participants, 23 from Organization A and 16 from Organization $B$, were included in the study. The age range was as follows: 30 or under = $5.8 \%, 31-40=48.1 \%, 41-50=36.5 \%$, and 51 or older $=9.6 \%$. Employees from Organization A averaged 4.5 years of management experience and employees from Organization $B$ averaged 10.1 years of management experience. Instruments

To assess learning acquired and retention of learning, an assessment tool (test) was designed (See Appendix A). The test was designed by the author of this study, a principal of the training company, the training program designer (an attorney), and the training instructor. The test consisted of 25 questions, 14 multiple choice aid 11 true/false. The content of the test was drawn from lecture material delivered during the course and from the program workbook and was representative of the program objectives. Two examples of true/false questions are: (1) Ethnic jokes are a form of harassment, and (2) In a sexual harassment lawsuit, the harasser is always named as a co-defendant along with the company.

To assess transfer of training, 16 questions were developed by the author of this study, a principal of the training company, the training program designer (an attorney), and the training instructor. The questions were designed to have yes/no answers and to give 
participants the opportunity to elaborate on responses. Examples of transfer of training questions are: (1) Do you feel yourself documenting more? If so, in what ways?, and (2) Is there anything you've done/observed since attending the program in regards to harassment in the workplace? The participants' responses were transcribed and rated by two training managers from a company not participating in the study. Responses that the training managers viewed as demonstrating transfer of training were scored a "l " and responses that were viewed as not representing transfer of training were scored a " 0 ". Inter-rater reliability was $100 \%$, meaning that both raters gave identical ratings to all participants.

\section{Design and Procedure}

Retention of Learning. A one-group pre-test/post-test design was employed to measure the acquired learning and retention of learning for both organizations (Goldstein. 1986). The pre-test was administered to participants at the start of the training program. prior to the introduction of the course objectives, and the first post-test was administered at the conclusion of the program. The post-test was given to those participants who had completed the pre-test and who had attended the entire training program.

For administration of a second post-test, participants who had completed both a pre-test and the first post-test were contacted by telephone and asked to participate in a follow-up evaluation procedure. Those participants that consented met with the experimenter approximately two months after the training and were given ten minutes to complete a second post-test.

Transfer of Training. To measure transfer of training, participants of the training program were interviewed. Those participants contacted by telephone to complete the second post-test were asked to be interviewed. Upon acceptance, the author of this study met with each participant at the participant's work site. The participants were informed of 
the study and were asked a series of questions (See Appendix B). All interview data was collected by the author of this study.

\section{Results}

Means and standard deviations of participants from both organizations are listed in Table 1. On average, scores from participants from both organizations increased between Time I and Time II and decreased slightly between Time II and Time III.

In order to test the first hypothesis, a repeated measures analysis of variance was performed to determine if there was a significant difference between the pre-test scores and the post-test scores of all participants. The independent variable was time period: Time I was at the beginning of the training program, Time II was immediately following the training program, and Time III was two months after the training program. Results were significant. $\underline{F}(2,102)=95.36, \underline{p}<.0001$. The mean at Time I (17.79) was significantly lower than the mean at Time II (21.79) and the mean at Time III (20.90). Specifically, participants had significantly higher scores after the training program than before the training program and they continued to retain significantly higher scores two months after the training program. This implies that learning occurred as a result of the course and that material learned in the course was retained two months after participants had completed the training program.

In order to determine if there was a significant difference in retention of learning between employees of Organization A and employees of Organization B, a repeated measures analysis of variance was performed. The independent variables were the organization, Organization A and Organization B. and the time period. The two-way interaction was not statistically significant, $\underline{E}(2,100)=.55, \underline{\mathrm{p}}=.58$. The main effect for organization was not significant, $\underline{F}(1,100)=3.86, \underline{p}=.0549$. The main effect for time period, however, was significant, $\underline{F}(2,100)=94.52, \underline{p}<.0001$, meaning that the increase in scores between Time I and Time II and between Time I and Time III was the same for 
Table I

Means and Staridard Deviations of Organization Scores by Time Period

\begin{tabular}{|c|c|c|c|c|c|c|}
\hline \multirow[b]{2}{*}{ Time } & \multicolumn{3}{|c|}{ Overall } & & & \\
\hline & $\underline{M}$ & $\underline{\mathrm{SD}}$ & $\underline{\mathrm{n}}$ & & & \\
\hline Time I & 17.79 & 2.25 & 52 & & & \\
\hline Time II & 21.79 & 1.36 & 52 & & & \\
\hline \multirow[t]{2}{*}{ Time III } & 20.90 & 1.79 & 52 & & & \\
\hline & \multicolumn{3}{|c|}{ Organization A } & \multicolumn{3}{|c|}{ Organization B } \\
\hline Time & $\underline{\mathrm{M}}$ & $\underline{S D}$ & $\underline{\mathrm{n}}$ & $\underline{\mathrm{M}}$ & $\underline{S D}$ & $\underline{\mathrm{n}}$ \\
\hline Time I & 18.27 & 2.54 & 26 & 17.31 & 1.85 & 26 \\
\hline Time II & 21.96 & 1.40 & 26 & 21.62 & 1.33 & 26 \\
\hline Time III & 21.31 & 1.74 & 26 & 20.50 & 1.77 & 26 \\
\hline
\end{tabular}


both organizations.

An unpaired t-test was conducted to determine if there was a significant difference in transfer of training between employees of Organization A and employees of Organization B. The independent variable was the organization. Results showed a significant difference between participants from Organization $A$ and participants from Organization $B, t(50)=$ 9.36, $\mathrm{p}<.0001$. Employees from Organization $\mathrm{A}(\underline{M}=6.35)$ exhibited a significantly higher degree of transfer of training from the program than employees from Organization B $(\underline{M}=2.73)$. Therefore, employees of Organization A applied their newly-acquired knowledge and/or skills in the areas of sexual harassment issues, wrongful termination issues, equal employment opportunities, and affirmative action to their day-to-day management roles more than did employees from Organization B.

\section{Discussion}

The purpose of this study was to examine the influence of corporate culture on the retention of learning and transfer of skills and knowledge learned in a formal training program. The first hypothesis in this study was that a statistically significant difference would be found between scores taken prior to the training program and scores taken after the training program, regardless of where the participants were employed. The results support this hypothesis. Specifically, scores taken immediately after the training program were found to be significantly higher than scores taken prior to the training program. Thus, it was demonstrated that leaming occurred as a result of the training program. Based upon these results, participants from both organizations showed an increase in test scores after attending the training. In order to establish if any further levels of evaluation were attained. as previously discussed in Kirkpatrick's model, this initial level of evaluation. Learning, must exist to allow for the transfer of learned skills and knowledge back to the work environment. 
The second hypothesis in this study was that, among the participants from Organization $A$, there would not be a statistically significant difference between scores taken immediately after the training and scores taken two months after the training. This would offer evidence of retention of learning. This hypothesis was also supported. Scores taken from participants from Organization A immediately after the training and scores taken two months after the training were not significantly different.

The third hypothesis of this study was that scores taken from the participants from Organization B two months after the training would be significantly lower than scores taken immediately after the training, establishing that participants had not retained their learning. Results yielded did not support this hypothesis. The scores of employees from Organization B did not decrease from immediately after the training to two months after the training. It was hypothesized that the corporate culture would have a negative effect on the retention of learning but, based on these results, an employee's organizational culture did not have a significant effect on the employee's ability to retain information learned in the training program.

One factor that could have impacted the above results was the difference in baseline scores measured before the training. The participants from Organization A scored slightly higher in the pre-test and maintained that higher knowledge level as reflected in their test scores. In effect, they started better and stayed better. This additional factor did not influence the results. Participants from both organizations retained the knowledge learned. regardless of organizational assignment.

The fourth hypothesis stated that participants from Organization A would report a significantly higher degree of transfer of training than participants from Organization B. Results showed conclusively that the transfer of training scores of the participants from Organization A were significantly higher than the scores of the participants from Organization B. Employees in Organization A reported that they had used the knowledge 
and skills learned in the training program back in their work environment. Kirkpatrick's third level of evaluation. Behavior, was reached by employees from Organization A. Results showed that the employees from Organization B reported a significantly lower degree of transfer of skills and knowledge acquired in the training program back to the work environment. Thus, employees from Organization B stopped their learning at Kirkpatrick's second level of evaluation. Learning, and did not apply their new knowledge and skills in their working performance.

\section{Implications of This Study}

From a practical perspective, there are several implications for organizations that can be noted from this study. Specifically, the successful retention of learning and transter of training within an organization can depend upon: (1) the structure and positioning of training departments in an organization, (2) incentives available to motivate employees to use acquired knowledge and skills, and (3) the relationship between the skills taught in a training program and a participant's job.

The structure and positioning of training departments in an organization. Upon examination of the two cultures, it is apparent that Organization A's approach to providing training programs is very holistic. The training program participants attended was included in an overall management curriculum. Managers were required to complete a series of training classes within the first two years of employment to remain in their positions or to be considered for promotion. In fact, the training department was named "Organization $\mathrm{A}$ University." Employees received catalogs outlining over twenty different courses offered. A separate training facility away from employees' work sites was provided so that employees would not be tempted to leave in the middle of a training program and return to their work areas. The training department employed full-time trainers, instructional designers, training coordinators, and training consultants. Enrollment in all training 
programs merited a letter from the President and Chief Executive Officer of the company expressing his support for each participant's attendance.

The training department at Organization B was in strong contrast to that of Organization A. It consisted of two employees, a training manager and a training coordinator. The department offered few training classes, all of which were required to ensure that the organization and the organization's employees met government requirements. The training program employed in this study was a stand-alone class not related to any of the other programs offered to employees.

Employees can deduce how important learning and transfer of their acquired skills are to an organization by the amount of resources that the organization has dedicated to the function. If an organization desires a return on their investment in the training department then it should be visible to an employee how important training is to the organization. Employees must be able to easily locate and enroll in classes that will help them perform their jobs better. Organizations that dedicate little or no resources to training will send the message to their employees that training is not valued by the company. Similarly. if it is difficult for employees to locate and enroll in classes that will assist them in performing their jobs better, employees may also come to the conclusion that their organization is not supportive of training. Organizations that take a strategic approach to designing a training function and make it an integral part of an employee's employment contract, however, are clearly sending the message to the employee that training is an important and vital part of the job and that learning is highly valued within the company.

It is key for organizations to understand that the value of providing training to employees is to improve their performance on the job. If providing training yields an increase in knowledge but a transfer of that knowledge does not take place. then the training is not very useful. The results of this study show that the organizational culture has an effect on the transfer of skills and knowledge to an employee's work performance. 
Including a training class in an overall curriculum of learning and providing a context for employees to apply their learning are important to ensure transfer of training and skills back to the job.

Organizations need to carefully position training programs to employees so they will understand the value in attending a training program, beyond meeting government guidelines. Not all organizations have the budget necessary to build a training department as large as Organization A's, however, there are other methods that can be employed to emphasize the importance of training to employees. For example, an organization could establish a tuition assistance program to enable employees to afford education outside of the organization. There are several public workshops that are offered in large metropolitan cities and brochures from these workshops could be circulated throughout other functional departments within the organization, with a clear message from the company that attendance at the training is valued by the company. In addition, it should be pointed out to employees how a particular training class will directly affect their work performance. performance appraisals, and promotional opportunities.

Incentives available to motivate emplovees to use acquired knowledge and skills. Employees of Organization A received certificates after completing each training course and a financial incentive after completing the overall training curriculum. Completion of classes and demonstration of acquired learning and skills back on the job were tied to promotions and other growth opportunities within the organization. If an employee wanted to be recognized and considered for additional responsibilities, he or she was given a set of classes to attend to learn new skills. Thus, the company made the employee aware of the need to demonstrate that he or she could competently handle the responsibilities associated with the new position.

For employees in Organization B, there were no visible incentives for employees to learn and apply new skills. The organization did not reward them for learning new skills 
and using them. A majority of the participants reported in the interviews that they had attended classes similar to this program at other times in their careers and that the information in this class was not very useful. In one interview, a participant reported that she was being sexually harassed by her manager. This same manager had attended the program and participated in this study. Other participants reported that they attended the class because it was mandatory, but they did not see that their organization was supporting the objectives and material contained in the training program. It was apparent to the participants that the organization's focus was on meeting the governmental requirement by having employees simply "fill a seat" in the classroom.

In this study, participants from Organization A had two incentives to attend the training program: a certificate of completion at the end of the course and recognition in the next performance review. In addition, there were two incentives for completion of the training curriculum: maintaining employment at the company and direct financial compensation, in the form of a bonus or paid time-off. Organization B had no incentives for an employee to complete the training or to use the knowledge and skills acquired.

An important factor in Adult Learning Theory focuses on the need for adults to understand how a training program is directly related to their work performance. "WIIFM" (what's in it for me) is a common term in the training and development industry. If employees do not understand the direct benefits of attending training, they do not become invested in learning. Organizations need to associate the skills and knowledge learned with an incentive so that participants are rewarded for transferring the skills learned in the training program back on the job. For example, core competencies to perform a job could be defined. Training programs associated with those core competencies could then be provided. For an employee to move into another position, he or she would need to complete the training classes that would provide the skills necessary to perform the core competencies of that position. Employees realizing that growth and promotion are 
associated with a training program are more apt to use the skills learned in the training classes.

The relationship between the skills taught in a training program and a participant's job. It is important that participants understand the relationship between the class material and their job performance. Organization A measured their managers' ability to handle situations that were directly related to the course material. Employee relations managers within the organization followed up with the participants of the class to see if support was needed in any situation. If managers failed to exhibit skills learned in the course. they received coaching on the correct method of handling a situation.

In comparison, Organization B did not follow up with their employees to ensure that they were using their new skills correctly. Employees were not made aware of how they could use their newly-acquired skills to reduce potential liability of the organization. Employee relations managers within the organization did not conduct follow-up interviews with the participants. In addition, employee relations managers did not emphasize that the skills participants had learned in the training program were important, even when a situation occurred in which participants could have directly used the new skills on the job.

It is essential for training participants to understand how their attendance, learning. and exhibition of acquired skills will affect their job performance. Larger organizations, such as the ones participating in this study, have the resources to establish core competencies and to build a relationship between the competencies needed to perform specific jobs and the training classes offered. However, it is possible for smaller organizations to build this relationship by strategic use of the management team. If the management team supports the content in the training programs and refers to the course content when coaching an employee or reviewing an employee's performance, the employee will see the direct relationship between the training program and their own performance. 


\section{Strengths and Limitations of This Study}

One of the strengths of this study is that two clearly-different corporate cultures were studied. Previous studies have focused on the effect of corporate climate within one organization and did not compare the cultures of two separate organizations. Furthermore. it was obvious from printed information, visual artifacts, and participants' responses and personal styles that these corporate cultures were very different. In addition, the quality of data gathered to demonstrate transfer of training was very descriptive. Employees from Organization A were more open to sharing stories about how they used the skills they had acquired and knowledge they had learned from the training program. It was evident that these participants were excited by the program and by the opportunity to learn. In comparison, the participants from Organization B were bothered by the time it took to be interviewed. They were more reserved about sharing any information regarding their behavior following the training program.

Another strength of the study was that several conditions external to the companies were held constant. An external training vendor was used to deliver the program. Because the training vendor was interested in measuring the effects of the training for marketing purposes, the vendor took great care to hold training conditions constant to get a true measure. The training vendor normally sells the training program delivered in this study to organizations to deliver internally, but for the purpose of this study all classes were delivered by the same instructor. Therefore, the material was presented in a consistent manner to employees from both organizations. The instructor took great care to wear the same color suit for each class. The program was delivered in the same outside facility for both organizations. The location, room size, temperature of the room, and the food provided were consistent for all of the classes.

There were a few limiting factors of this study. One of these factors was the sample size of the study. Both organizations employ approximately 2000 workers. but 
only 26 employees from each organization participated in the study. It is possible that the 26 participants from each organization were not a representative sample of the different corporate cultures. Similarly, it is unknown if the same results would have been achieved if all of the original 69 training participants would have participated in the study.

A second limiting factor of this study is the differing characteristics of the organizations' employees. Participants from Organization B averaged over 10 years of management experience while participants from Organization A averaged 4.5 years of experience. In addition, $61.5 \%$ of participants from Organization A were under 40 years of age compared to $46 \%$ of participants from Organization B. It is unknown whether the difference in management experience or age between the participants from the two organizations would have affected the findings of this study. For example, it is possible that participants from Organization B, who average more years in management than participants from Organization A, may have more difficulty learning new skills and adapting them to the work environment. These participants may have learned these skills in previous training programs and thus not have shown a transfer from this particular program. because they were already demonstrating these skills as a result of a previous training program they had attended.

Another limiting factor was the content of the training program. The program utilized for this study focused on sexual harassment, wrongful termination, equal employment opportunities, and affirmative action guidelines. If a manager did not have the opportunity to use the skills he or she had acquired in these areas back on the job, transfer of training would not have been reported. Therefore, the program was not presented in a just-in-time manner, meaning that it was not always possible for a participant to immediately return to the work environment and apply the skills learned. For example. if the participants of the classes were not exposed to a situation involving sexual harassment 
upon return to the work environment, then they would not have had an immediate opportunity to apply their newly-learned skills and knowledge in this area.

\section{Future Evaluations}

Several recommendations for future evaluations could be used to build on the results obtained in this study. One recommendation would be to involve the same design and methodology utilized in this study. but to use a different management training program. Utilizing a training program that is directly relevant to participants' jobs and that has a high degree of practical application would present more opportunities for participants to use the skills acquired in the training back on the job. For example, participants completing a training program on performance management just prior to writing performance reviews for their subordinates may show different results, as the participants would then have an immediate opportunity to apply the skills learned.

In addition, if similar studies in the future were to involve larger sample sizes from the organizations studied and were to match participants for age and management experience. results from these studies would be strengthened. Matching participants by age and management experience would eliminate any differences that may occur due to differing backgrounds, such as difficulty adopting new skills due to a longer tenure in management. Similarly, using a larger sample size would increase the probability that representative samples of participants from each organizational culture were obtained.

\section{$\underline{\text { Conclusions }}$}

Conclusions from this study indicate that the corporate culture within an organization can have a strong effect on the transfer of new skills and knowledge learned in a training program back to the job. It is important for organizations to realize that in order to derive the full benefits from training programs provided to employees, a work environment supportive to training must be offered. 


\section{References}

Alexander, G. (1987. February). Establishing shared values through management training programs. Training and Development Joumal, pp. 45-48.

Baldwin T. T. \& Ford J. K. (1988). Transfer of training: A review and directions for future research. Personnel Psychology, 41, pp. 63-105.

Black. A. (1991). Evaluation in training. ASTD Training Camp Resource Workbook. San Francisco, CA: Author.

Carnevale, A., Gariner, L.. \& Villet, J. (1990). Training in America: The organization and strategic role of training. San Francisco, CA: Jossey-Bass.

Deal, T. E. \& Kennedy, A. A. (1982). Corporate culture: The rites and rituals of organizational life. Reading, MA: Addison-Wesley.

Denison. D. (1992). Corporate culture and organizational effectiveness. New York, NY: John Wiley \& Sons.

Eicher, J., Johns, J., \& Bearley, W. (1996). The learning style profile: Developing the learning organization. Del Mar. CA: HR International.

Fleishman, E. (1953). Leadership climate, human relations training, and supervisory behavior. Personnel Psychology, 6, pp. 205-222.

Fleishman, E. A., Harris, E. F. \& Buntt, H. E. (1955). Leadership and supervision in industry. Columbus, $\mathrm{OH}$ : Ohio State University, Personnel Research Board.

Ford, J. K., Quinones, M. A., Sego, D. J., \& Sorra, J. S. (1992). Factors affecting the opportunity to perform trained tasks on the job. Personnel Psychology, 45. pp. $511-527$.

Garavagia, P. (1993, October). How to ensure transfer of training. Training and Development Journal. pp. 63-67. 
Gilbert, T. F. (1978). Human competence: Engineering worthy performance. New York: McGraw Hill.

Goldstein, I. (1986). Training in organizations (2nd ed.). Monterey. CA: Brooks/Cole.

House, L. (1968). Leadership training: Some dysfunctional consequences. Administrative Science Quarterly, 12, pp. 556-576.

Huczynski, A. A. \& Lewis, J. W. (1980). An empirical study into the learning transfer process in management training. Journal of Management Studies, 17, pp. 227240.

Kearsely, G. (1982). Costs, benefits, and productivity in training systems. Reading, MA: Addison-Wesley.

Keppel, G. (1982). Design and analysis: A researcher's handbook. Englewood Cliffs, NJ: Prentice-Hall.

Kirkpatrick, D. (1994). Evaluating training programs: The four levels. San Francisco, CA: Berrett-Koehler.

Kotter, J. P. \& Heskett, J. L. (1992). Corporate culture and performance. New York, NY: The Free Press.

Litwin, G. \& Stringer, R. (1968). Motivation and organizational climate. Boston. MA: Harvard University Press.

McCune, J. (1994, April). Measuring the value of employee education. Management Review, pp. 10-15.

Noe, R. A. \& Schmitt, N. (1986). The influence of trainee attitudes on training effectiveness: A test of a model. Personnel Psychology, 39. pp. 497-523.

Ouchi, W. (1981). Theory Z. Reading, MA: Addison-Wesley. Pascale, R. \& Athos, A. (1981). The art of Japanese management. New York: Simon \& Schuster. 
Peters, T. \& Waterman, R. H. (1982). In searci of excellence. New York: Harper-Row.

Phillips, J. J. (1983). Handbook of training evaluation and measurement methods. Houston, TX: Gulf.

Rouiller, J. Z. \& Goldstein, I. L. (1992). The relationship between organizational transfer climate and positive transfer of training. Human Resource Development Quarterly. 4. pp. $377-390$.

Rummler, G. A. (1976). The performance audit. In R. L. Craig (Ed.), Training and development handbook (2nd ed.). New York: McGraw-Hill.

Sackman, S. A. (1991). Culture knowledge in organizations: Exploring the collective mind. Newbury Park, CA: Sage.

Schein, E. H. (1985). Organizational culture and leadership: A dynamic review. San Francisco, CA: Jossey-Bass.

Shandler. D. (1996). Reengineer the training function. St. Louis, MO: St. Lucie Press.

Singer, R. (1996, Winter). Lecurette: Introduction to training and development. Presented at University of California, Santa Cruz Extension, Santa Cruz, CA.

Tannenbaum, S. I. \& Yukl, G. (1992). Training and development in work organizations. The Annual Review of Psychology, 43, pp. 399-441. 
Appendix A

\section{EVALUATION TOOL}

MDS is interested in evaluating the effectiveness of the training program Managing Within The Law. This evaluation tool was designed to see if we have meet our objectives set at the beginning of this workshop. This is not a test. Please circle the answer most appropriate for the question based on your present knowledge. Some questions are similar to the evaluation tool conducted prior to the workshop. You should spend no more than ten minutes answering these questions.

1. Having a legitimate business reason is important when making employee related decisions. Which of the following is not considered a legitimate business reason?
a) employee qualifications.
d) business conditions.
b) employee performance.
e) employee appearance.
c) company rules.

2. In hiring situations, it is permissible to offer unequal salary compensation to individuals filling similar positions on the basis of their
a) knowledge, skills, and abilities.
d) a \& $c$
b) education.
e) all of the above.

c) experience.

3. Which one of the following questions is appropriate and permissible to ask in an interview?
a) Have you ever been arrested?
b) What are your plans for your future career?
c) Are you a citizen?
d) What are your child care arrangements?
e) All of the above.

4. Building rapport is important in the interview process. Which one of the following questions is inappropriate and possibly illegal during the interview?
a) Did you have trouble finding our office?
b) What did you excel in your last job?
c) How many children do you have?
d) Would you like to enhance your skills in other areas?
e) How were your accommodations?

5. Good business sense and the law dictate that employees should work in a discrimination free environment. A manager should not discriminate when choosing an employee to participate in a training program. Which example is a reason not based on discrimination?
a) they are an immigrant
b) if they've been on disability recently
c) their amount of time left with the company
d) their productivity
c) their age

6. Under Affirmative Action guidelines, employees who are disabled should be given "reasonable accommodation". What "reasonable accommodation" should a manager try to provide for their employees who are physically disabied?
a) Allowing the employee to work Saturdays, if they can't work one day during the week.
b) Allowing the employee to have flexible working hours.
c) Allowing time off for drug and alcohol rehabilitation programs.
d) All of these.
e) None of these. 
7. If you receive a complaint of sexual harassment from one of your subordinates regarding another subordinate, which is the most appropriate action to take?
a) Listen to the complaint and inform the accuser if it happens again you'll take action.
b) Casually talk with the accused subordinate so as not to embarrass them.
c) Have a joint conference of the accused and accuser and then call Human Resources.
d) Discuss the accusations with the accuser and then call Human Resources.
e) Monitor the accused employee's behavior for a month and then report all actions to Human Resources.

8. Which example is a form of sexual harassment?
a) Patting an employee's shoulder to tell them they did a good job on a project.
b) Asking a co-worker for a date once.
c) Casually complimenting a female employee's legs while she is wearing a mini-skirt.
d) Making an obscene jesture at your telephone system.
c) Sending a strip-o-gram to an employee as a birthday gift.

9. The most appropriate first step to take when you observe poor performance of an employee is to
a) give a written waming.
d) call Human Resources.
b) give a verbal waming.
c) give verbal counseling.
e) point out all their faults in hopes that they will quit first.

10. When interviewing applicants for a receptionist position, it is okay to not hire someone
a) because the applicant is a man and it is a women's position.
b) because the applicant speaks with a heavy accent and you can't understand what they are saying.
c) because the applicant is black and your customers have made reference that they prefer dealing with white employees.
d) all of the above.
e) none of the above.

11. Under Affirmative Action guidelines, certain groups of people are identified as a protected class. Which of the following groups is not protected under AA law.
a) Sex
b) Handicapped
d) Religion
c) Race and color
e) Vietnam-era veterans

12. Under state and/or local laws, you are required to give employees time off for all of the following reasons except
a) to enter a drug rehabilitation program.
b) to recover from work related injury.
c) to have a child.
d) to arrange child care.
e) to obtain medical attention for a disability.

13. Terry, in your work group, is an outstanding performer and very friendly. He likes to give hugs and tell jokes. It does not bother any of his co-workers; they are used to it and accept it as part of his personality. A new employee, Amy, is bothered by this behavior. She has mentioned on occasion that she is disturbed by it. Terry and everyone else feels this employ$\propto$ is being supersensitive. What is the most appropriate action to take in this situation?
a) Amy should get used to it and not say anything since Terry has seniority.
b) You should counsel Amy and explain that this is the way it is in the department she might want to take some time to adjust to it.
c) You should talk with Terry regarding his behavior.
d) You should choose to relocate Amy so that she does not have contact with Terry.
e) You should contact Human Resources and inform them of this new problem employee. 
14. There are four key concepts to managing people legally. Which one of the following is not one of the key concepts?

a) Be consistent.

b) Have a legitimate business reason for your decision.

c) Double check everything with your supervisor.

d) Document events.

e) When in doubt, call an expert.

T F 15. Telling a new employee that after a 90 day probationary period they will be a permanent employee could result in a wrongful temination lawsuit if the employee was discharged.

$\mathbf{T} \mathbf{F}$

16. If you wish to discipline or terminate an employee for being constantly tardy, you should document the arrival times of all employees with similar positions in the department in addition to the tandy employee.

$\mathbf{T} \mathbf{F}$

17. Several of your employees have been coming to you lately commenting on the attitude of another employee, Dave. They say he has a bad attitude and they don't like working with him. You could terminate Dave on these grounds.

$\mathbf{T} \quad \mathbf{F}$

18. According to Affimative Action guidelines, you must hire a certain number of minorities, even if they are not fully qualified.

$\mathbf{T} \quad \mathbf{F}$

19 According to Affirmative Action guidelines, you can not terminate an employee who presently has an alcohol and/or drug addiction but has not used alcohol or drugs for the past 6 months.

T $\quad \mathbf{F}$

20. Ethnic jokes are a form of harassment.

T $\quad \mathbf{F}$

21. An employee who spreads false stories about the sex life of a co-worker could be sued for defamation.

$\mathbf{T} \mathbf{F}$

22. Love affairs between employees can lead to charges of sexual harassment.

T $\mathbf{F}$

23. The company could be held responsible for sexual harassment of an employee by an outside contractor.

T $\quad \mathbf{F}$

24. In a sexual harassment lawsuit, the harasser is always named as a codefendant along with the company.

$\mathbf{T} \quad \mathbf{F}$

25. If an employee files a wrongful termination lawsuit, the firing manager and company are normally named in the lawsuit.

Please fill in the blanks and check the most appropriate answer.

Company

Department

Number of years in management
Sex: M F

Age group: $\quad 20-30 \quad 30-40 \quad 40-50$

$50-60 \quad 60+$ 
Appendix B

\section{Transfer of Training Interview Questions}

Script to be read to participant:

Management Development Systems is interested in evaluating the quality of our programs. They designed and delivered the Managing Within The Law training program which you attended. I would like to get some feedback from you regarding this program to see if we have met our objectives and to identify the areas that we might improve. Everything you tell me is confidential. I will not repeat nor quote anything you say without your direct permission. Your company and superiors do not know who is chosen to participate in this study: therefore. feel free to confide in me any examples you would like.

1. What one thing do you remember most about the program Managing Within The Law (MWTL)?

2. Do you feel participating in the MWTL program was a valuable experience for you? Why or why not?

3. Do you recall who instructed the program you attended?

4. The objective of the program is to provide managers with practical information and skills necessary to perform their jobs legally. Do you feel this was accomplished?

5. The program identifies some frightening responsibilities of a manager. Our goal is to take the fear out of managing. Do you feel this was accomplished?

6. The program offered tools for your use that could be utilized in employee-related situations. Some tools were the listen/solve or how to write a disciplinary memo. Have you used those tools? Are they valuable? What other tools could be provided?

7. Have you changed anything in your management style since the program? If so, could you give me some examples?

8. Have you changed any of your behaviors in the interview process? Do you define criterion for the position and use a pre-set list of questions that are job-related?

9. Do you feel comfortable in the interview process?

10. Is there anything you've done/observed since attending the program in regards to harassment in the workplace?

11. Do you feel yourself documenting more? If so, in what ways?

12. Is there anything you've done since attending the program, in regards to AA in the workplace?

13. Your company wants to provide a better workplace for its employees. One way to accomplish this is by offering MWTL to its managers. Do you feel the corporation is reinforcing this training? If so, how?

14. Do you remember the four key concepts for managing legally that the program focused on?

15. What other kinds of information do you feel needs to be covered in this program?

16. Is there anything we can do to make the program more beneficial to future participants? 
TO: $\quad$ Lucia J. Erwin 1930 Almaden Rd., \#62

San Jose, CA 95125

FROM :

serena w. stanford yerema it. AAVP, Graduate Stuqhes \& Research

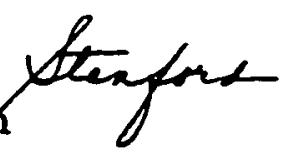

DATE: $\quad$ September 27, 1996

The Human Subjects-Institutional Review Board has approved your request to use human subjects in the study entitled:

\section{"The Effect of Corporate Culture on Retention of Learning and Transfer of Training"}

This approval is contingent upon the subjects participating in your research project being appropriately protected from risk. This includes the protection of the anonymity of the subjects' identity when they participate in your research project, and with regard to any and all data that may be collected from the subjects. The Board's approval includes continued monitoring of your research by the Board to assure that the subjects are being adequately and properly protected from such risks. If at any time a subject becomes injured or complains of injury, you must notify serena Stanford, Ph.D., immediately. Injury includes but is not limited to bodily harm, psychological trauma and release of potentially damaging personal information.

Please also be advised that all subjects need to be fully informed and aware that their participation in your research project is voluntary, and that he or she may withdraw from the project at any time. Further, a subject's participation, refusal to participate, or withdrawal will not affect any services the subject is receiving or will receive at the institution in which the research is being conducted.

If you have any questions, please contact me at (408) 924-2480. 